\title{
Engaging Staff in Curriculum Change: Reflections from an Accounting Ethics Initiative
}

\author{
Sue Wright (Corresponding author) \\ Faculty of Business and Economics, Macquarie University \\ North Ryde, N.S.W. 2109, Australia \\ Tel: 61-2-9850-8521Ｅ-mail: sue.wright@mq.edu.au
}

Philippa Byers

Faculty of Arts, Macquarie University

North Ryde, N.S.W. 2109, Australia

Maria Dyball, James Hazelton \& Renee Radich

Faculty of Business and Economics, Macquarie University

North Ryde, N.S.W. 2109, Australia

$\begin{array}{lc}\text { Received: September 8, } 2011 & \text { Accepted: October 11, } 2011 \quad \text { Published: November 1, } 2011 \\ \text { doi:10.5539/ass.v7n11p93 } & \text { URL: http://dx.doi.org/10.5539/ass.v7n11p93 }\end{array}$

This research is supported by a Macquarie University Strategic Curriculum Innovation Grant.

\begin{abstract}
This paper identifies the challenges associated with engaging staff in curriculum change, using the context of systematic inclusion of ethics in the accounting curriculum of a major Australian metropolitan university, and offers some suggestions as to how these challenges might be overcome. We characterize the inclusion of ethics in the accounting curriculum as 'pluri-disciplinary' following the typology of Davies and Devlin (2007) and draw on 22 interviews with accounting academics to examine curriculum change in a pluri-disciplinary context. We find that key staff concerns are the impact on broader accounting discourse, assignment of teaching responsibilities, curriculum content, and identification of who is ultimately responsible for the curriculum change. The responses indicate that staff would like to be equipped to confidently deliver ethics content and to have material relevant to a technically-focused student cohort. One means of achieving this might be to involve ethics experts in developing and delivering foundational material early in the curriculum and having accounting staff teach applications of this material in the latter stages. Our observations might also be of interest to those seeking to embed other 'soft' skills (such as communication, critical thinking and sustainability) within a technical curriculum.
\end{abstract}

Keywords: Interdisciplinary, Pluri-disciplinary, Business ethics, Curriculum

\section{Introduction}

A widespread response to the corporate collapses of the early 2000's has been the call for accountants and auditors to be taught ethics. This response is based on two premises: that the collapses were caused by unscrupulous behavior by these professionals, and that such behavior can be addressed by education. In 2004, the International Federation of Accountants (IFAC) included International Education Standard 4 (IES4): Professional Values, Ethics and Attitudes in the suite of educational standards that 164 member bodies in 125 countries agree to meet. The Association to Advance Collegiate Schools of Business (AACSB) accreditation requires that ethics be incorporated into accounting courses (Williams and Elson, 2010). Ethical theories, codes of conduct, questions and dilemmas have been added to the content of popular accounting textbooks, and many universities have included some ethics to their accounting curricula, either as part of an existing subject or as a 
specialist subject. But what are the challenges facing instructors of business ethics, and how can the instructors be engaged in curriculum change to ensure that the changes are sustained?

This paper considers the views of academics on the call for inclusion of (more) ethics in the accounting curriculum. It draws on several approaches to characterizing a disciplinary combination, and ways of teaching ethics, to theorise and explain the responses of a group of academics before the inclusion of more ethics content into the accounting curriculum in a planned and co-ordinated manner.

Section two provides an overview of the literature in this area. Section three describes our interview research method and section four provides results. The final section summarises the challenges of engaging staff in curriculum change, and presents possible solutions.

\section{Literature review}

While the formal study of ethics can be traced at least as far back as Ancient Greece, the study of Business Ethics did not emerge as a distinct domain until the 1970s. Prior to the emergence of the first academic journal in the area (the Journal of Business Ethics, which started in 1982), business ethics research was published in general management journals. This section explores the best way to describe the disciplinary combination of ethics and accounting, the nature of which will affect the way that the combined discipline is viewed by those who are working with it.

Like other disciplines, accounting "provides the structure of knowledge that trains and socializes members" (Beyer and Lodahl, 1976, cited in Davies and Devlin, 2007, 3). The inclusion of ethics into the accounting curriculum can be characterized in a number of ways. These include:

(a) Interdisciplinary

(b) Multidisciplinary or para-disciplinary

(c) Cross-disciplinary

(d) Pluri-disciplinary

Interdisciplinary is a generic term that describes 'the interaction among two or more different disciplines' (Berger, 1972, 25, cited in Franks et al., 2007), or 'the appropriate combination of knowledge from many different specialties - especially as a means to shed light on an actual problem' (Brewer, 1999, 328, cited in Franks et al., 2007). Several papers (e.g. Davies and Devlin, 2007, Foster, 1999) have finessed this term to distinguish different ways of interacting or combining disciplines.

The term 'multidisciplinary' implies the least connection between the disciplines. It is an approach in which many discrete and autonomous disciplines co-exist. For a research project, different disciplines would contribute independently to the problem at hand, with no new disciplinary insights emerging. Foster $(1999,365)$ describes this approach to interdisciplinarity as 'para-disciplinary', which he defines as 'a creative co-presence of mutually respecting real disciplines'.

Cross-disciplinary studies describe the investigation of a new topic that is normally outside the field of study of the contributing disciplines, which is investigated with no co-operation from others in the area of study concerned. Again, new disciplinary insights do not normally emerge.

The most interaction between pre-existing disciplines is termed 'pluri-disciplinary', in which 'two or more disciplines combine their expertise to jointly address an area of common concern'. (Davies and Devlin, 2007, 6) The area of common concern could not be addressed by either discipline in isolation, and there is often a transfer of techniques and methodologies.

Business ethics is best described as pluri-disciplinary, in which both business/accounting academics and philosophy academics jointly address the concerns of the business world, governments and society regarding the behavior of accountants and auditors. Much of the extant research is in education. Ethical theories are applied to the accounting environment, to draw conclusions about the most appropriate way of intervening in the educational process to affect future accountants' values, ethics and attitudes.

What are less frequently discussed are the challenges of engaging staff in teaching business ethics; more complex to teach because it is pluri-disciplinary. Accounting staff are required to teach outside their area of expertise, and to present authoritatively on ethical theories. The following paragraphs draw on the literature on teaching in interdisciplinary settings, to interpret the responses of the teaching staff to ethics education.

There has been a limited discussion in the literature on how to achieve interdisciplinarity, and the associated resistance that it meets. An earlier debate in the literature on whether business ethics should be taught by 
accountants or philosophers is summed up by Frederick (1998): "Who is qualified to teach business ethics?" (575). As a pluri-discipline, business ethics would rarely be taught by an instructor qualified in both accounting and ethics, who would therefore not be challenged by this rhetorical question. Indeed most instructors would provide some resistance to teaching in such a pluri-discipline for this reason. Franks et al. (2007) synthesise more recent thoughts on this topic. At the level of teaching a subject, such resistance may be a result of

(i) differences in the characteristics of disciplinary knowledge,

(ii) differences in approaches to student learning, and other disciplinary traditions (Bradbeer, 1999, cited in Franks et al. 2007), or

(iii) differences in the academic language of the discipline (Brewer, 1999, cited in Franks et al., 2007).

Sustained interaction between academics in different disciplines is needed to counter the usual resistance to such a change (Braddock et al., 1994, cited in Franks et al., 2007).

Following an evaluation of an interdisciplinary health care accounting class, Steadman (2000) assembles a list of "lessons learned", to assist future instructors in designing interdisciplinary subjects. Williams and Elson (2010) provide a framework for instructors who are developing an interdisciplinary course in business ethics for the accounting curriculum. Steadman advocates:

(i) the use of guest lecturers (Williams and Elson (2010) suggest a team approach)

(ii) discussions of content between all instructors,

(iii) teaching to the lowest level of knowledge among the students,

(iv) student involvement though presentations, team-work, the use of cases and problems (Williams and Elson (2010) also recommend group work and the use of case studies)

(v) inclusion of students from a variety of different courses,

(vi) early planning by the teaching team,

(vii) sufficient administrative support, and

(viii) willingness to listen to criticism to improve in the future.

Davies and Devlin (2007) raise a number of concerns for instructors who want to teach interdisciplinary material to their students. The first is 'cognitive maps', or the way of viewing the world that is unique to each academic discipline. Can a student or instructor adopt a new cognitive map once the first has been learned? Second, the student and instructor must acquire a new discipline-specific language. Emerging from these two concerns is the notion of 'idea dominance' in which proponents of a discipline can identify the key ideas of their discipline, having both the knowledge and the 'structure of knowledge' to define legitimate questions and to solve them.

Nikitina (2006) uses a Habermasian approach to distinguishing broad disciplinary areas and the strategies that would be most suitable for interdisciplinary teaching in each. The humanities (or social sciences), in their pursuit of knowledge about humans and their behaviors, are recommended to use a contextualizing approach, in which the disciplinary material is embedded in the fabric of the time, culture and personal experience. The (empirical and analytical) sciences are recommended to use a conceptualizing approach, in which core concepts that are central to all of the relevant disciplines are identified. The applied sciences are best suited to problem-centring, in which "messy real-life problems that require more than one discipline to solve" (Nikitina, 2006, 253) are central to the interdisciplinary approach.

Nikitina (2006) concludes by advocating the use of more than one strategy where possible. Of her three strategies, it is problem-centring that seems most helpful to the combination of accounting and ethics, although elements of contextualizing and conceptualizing are also helpful. In problem-centring, the instructor uses an "ill-structured real world problem as an axis of connection among disciplines" (Nikitina, 2006, 263). The aim of this approach is to attack and resolve the problem. Because it is the study of ethics that is being combined with accounting, such a resolution would be indoctrinating if introduced at the level of the class. To the extent that problems are resolved between these disciplines, such a resolution must be at the level of the individual. At this level, learning becomes personally meaningful and highly motivated by a desire to resolve an important social concern. 


\section{Method}

Twenty-two members of an accounting department of over sixty full-time academics at a major metropolitan university in Australia were interviewed in 2007. Interviews were conducted by a member of the research team who is not an accounting academic. Ethics approval for the interviews was obtained from the university's ethics committee. Five questions were asked:

1. How would you describe the objectives and hoped-for outcomes for student of the ethics education component of your unit?

2. How do you think ethics education should be delivered within the undergraduate accounting curriculum in general?

3. Who do you think should teach ethics to accounting students, and what preparation if any is required in order to teach it?

4. Do you have a view about any difficulties or barriers that accounting students in general may face in tackling ethics education, or that particular groups of accounting students may face in tackling ethics education?

5. Is there anything else you would like to add regarding the issues raised by these questions?

Interview responses were recorded, transcribed and then de-identified and summarized by the interviewer, before being made available in this format to the remainder of the research team. Consideration of confidentiality necessitated the accounting academic members of the research team not having access to the full transcripts. Some members of the research team were also interviewed. Quotes included in the following section are from these summaries.

\section{Results}

Overall the interviews demonstrate that some of the potential points of resistance identified in the broader interdisciplinary literature are clearly evident in the pluri-disciplinary combination of ethics and accounting. Many staff identified the factors that underpin resistance as concerns. Gaps in their disciplinary knowledge and differences in their approaches to student learning were common themes. For example, respondents (8) and (3) commented that "tutors should be trained in educational approaches", although this might be "hard to organize", indicating that differences in approaches to student learning, as identified by Bradbeer (1999, cited in Franks et al., 2007) are a real concern. Others supported this factor as important. For example, respondents (9) and (13) identified that "staff are not prepared for practical discussions of ethics", for which they "need training on facilitating discussions" (13) and (14), and to know about "theories and ethical development" (13). Consistent comments include "Staff have not been taught ethics themselves" (14) and (16), and "tutors need assistance" (4). Insightfully, one interviewee noted that members of staff need to be "aware of their own biases" (14). Respondent (20) suggested that "new tutors need a yearly workshop to explain the theoretical aspects from philosophy, and how to combine this holistically from first to third year", which accords with Bradbeer's identification of differences in characteristics of disciplinary knowledge as a concern. In fact, nine of the twenty interviewees expressed the view that ethics topics should be taught by staff who have expertise, training or a special interest in the area. Respondent (8) summed it up, as "Ethics is hard to teach".

Interestingly, there are two notable differences between the factors identified in the literature as causes of staff resistance, and the comments of the interviewees. No-one identified differences in the academic language of the discipline as a specific concern. However, respondent (3) identified difficulties with assessments and the large number of tutors as problems. One respondent (5) suggested the use of take-home assignments, supporting the view that assessment is a concern.

From Steadman's and Williams and Elson's list of lessons learned, interviewees identified the need for the use of cases and problems. Respondent (3) noted the need for "good ethics resources that encourage students to engage with broader ethics issues". Others used words like "quality" (9) and (18), "current" (10) and (11), and "up to date" (16). None of the other lessons were identified by the interviewees, which is surprising. These staff members did not appear to feel responsible for the on-going inclusion of ethics in accounting education, but rather to be coping with it on a semester-by-semester basis, which suggests that it is something that they do because they are asked to, rather than because they have embraced it. This may be a consequence of the pluri-disciplinary nature of the combination, and the extent to which business ethics combines expertise in accounting which they have, with expertise in philosophy which they do not have. 
The interviews with accounting teaching staff that inform this article also reveal a diversity of opinions about teaching strategies, and some commented on the difficulty of a scholar of one discipline thinking in the manner of another discipline. Interviewees provided suggestions about teaching strategies that would assist accounting students to understand the pluri-discipline of accounting and ethics. Specific comments were made on integration and the nature of the material.

Consistent with Davies and Devlin's suggestion that bridging or intensive preparatory programs be integrated into the curriculum (Davies and Devlin, 2007), respondent (4) wanted to "include ethics in existing units so that the students could understand it in context, not just in theory". Respondent (9) identified an advantage of pluri-disciplinary teaching: "Experience of it will broaden our knowledge". Respondent (1) suggested a "situated ethics approach to encourage students to reflect on their own values". Others saw further benefits from a contextualized approach (20), such as students developing a "comprehensive rather than a compartmentalized view" (18). Frequent suggestions were to use current issues (4) and (8) and real-life examples (20).

However, on the question of the inclusion of ethics theory in accounting units and whether students should be taught by accountants or philosophers, there was less consensus. This indicates some concerns about accounting academics adopting the cognitive maps and language of philosophers on the one hand, and on the other hand, some reluctance to cede ground to the philosophers on the idea dominance in accounting.

Some were uncomfortable with accountants teaching ethical theories, indicating that ethics should be a stand-alone course provided by philosophy (15). This relates to the previously cited comments about discipline knowledge. Others were uncomfortable with philosophers having too much input into the accounting curriculum, stating that "students would not need to learn theory or about philosophy" (17) and (20) and that ethics should be included in the accounting units (4). Respondent (1) stated "Accounting makes it easy to teach ethics, as there are so many opportunities to discuss ethics". Respondent (18) held that the case study method needs to be taught by accounting academics, who really understand accounting issues. These comments reflect resistance to changes in the cognitive map of accounting, and a desire to maintain ownership and control of the accounting discourse.

In relation to Nikitina's (2006) suggestion that the most suitable teaching strategy for business ethics is real world centring, many of the respondent reflected a preference for case studies. This point was stated explicitly by respondents (3), (5), (6), (10) and (18): "Cases work best". The need for those cases to reflect the real world was articulated in the following comments: "Ethics should always be discussed with concrete examples first" (2), and "Tie ethics to what is really happening" (11). Respondent (9) provided a clear advantage of this approach: "Its only when they see how things relate to the real world that they get interested". There was also recognition of the advantage in terms of appropriate assessment techniques. Respondent (18) stated "case studies are most effective in terms of assessment".

In summary, four concerns emerge from the interviews with accounting academic staff prior to the introduction of ethics to the accounting curriculum in a systematic manner. They are

1. Impact on accounting discourse: As a pluri-disciplinary combination, the teaching of business ethics is less about a new disciplinary area being developed, and more about ethics being added to the accounting discipline. The outome of that "addition", on the spectrum of integration to appendix, reflects the ease with which the accounting academics have met this new requirement. Note that this challenge is asymmetrical between accountants and philosophers. The philosophers' discourse remains largely un-impacted by business ethics, whereas the accountants' discourse may be substantially impacted.

2. Who does the teaching: If it is the accountants who teach business ethics, they may struggle with the theory. If it is the philosophers, they may struggle with credibility and context to an exclusively accounting audience.

3. What to teach: Accounting instructors need to decide what to teach, how to teach it, and how to assess it. They are challenged by the need to use current and real-life examples, to contextualize the theory, and to integrate business ethics across the curriculum.

4. Who is responsible: Many of the instructors or potential instructors did not indicate an on-going commitment to the pluri-discipline, which risks its omission from the curriculum in future years. Comments that indicate a coping response, based on requirements, are: "Someone to tell me how to relate ethics to my field of accounting" (8) and "I do it because I have to" (16). Spain et al. (2005) share a teaching approach to business ethics in which this was a primary concern: "that the business faculty 
would not fully support this concept since it required them to allot valuable class time for the discussion and integration" (14). The absence of considerations similar to Steadman's list of lessons learned supports that this is a major concern for successfully engaging staff in curriculum change.

\section{Conclusion}

This article has drawn on staff interviews to identify challenges with engaging staff in curriculum change, in the context of introducing ethics to the accounting curriculum in an Australian university. Those challenges are concerns about the impact on broader accounting discourse, assignment of teaching responsibilities, curriculum content, and identification of who is ultimately responsible for the curriculum change.

The difficulties in integrating ethics education within the accounting curriculum discussed above echo the challenge of integrating other non-technical content such as generic skills and sustainability. In terms of the latter, in an Australian context Thomas (2004) notes teaching staff indifference towards sustainability (coupled with insufficient support) resulted in largely superficial outcomes. These issues have also been observed in other locations such as the Philippines (Segovia and Galang, 2002), Costa Rica (Segreda, 2002), and Russia (Verbitskaya et al., 2002). The linking of so-called 'soft skills' to technical content is also critical for student engagement (Hazelton and Haigh, 2010).

Overcoming these challenges involves the initial commitment of university leaders, and the emergence of a 'champion' for the cause. The support of university leadership and management is essential to provide funding and time/space in the curriculum. Then the concerns of who does the teaching and what to teach can be addressed, using resources suggested in the literature and/or developed for the specific setting. Specific factors that can be thus supported include training, curriculum development, resources development, discussions between philosophers and accountants re content and assessment, and so on. This suggestion accords with the view of Braddock et al. (1994, cited in Franks et al. 2007), which is that the key to countering resistance to change in such a situation is sustained interaction between the academics.

The broader concerns of the impact on the accounting discourse and who is responsible (sustainability of the initiative) can be met if there is an effective champion who is willing to engage in discussions with faculty, presentations to stakeholders within and outside the institution, and to be a planner for both the short-term success and the long-term sustainability of the pluri-disciplinary innovation. The champion's role is to weaken the resistance of other instructors, through energy and vision. Of course, it is necessary for all accounting staff to develop positive attitudes to business ethics in the curriculum, once expertise is developed and positive student outcomes are achieved (Avramidis and Norwich, 2002).

Finally, one other means of addressing these concerns might be to involve ethics experts in developing and delivering foundational material early in the curriculum and having accounting staff then teach applications of this material in the latter stages. This approach would enrich the quality of foundational material and might therefore enable subsequent case studies to be more nuanced and hence more credible and useful to students. It would also mean that more accounting staff have the 'last word' in the curriculum, and inclusion of ethics at this juncture would have symbolic as well as practical value.

As noted above our findings may have relevance not only for others seeking to further integrate ethics into the accounting curriculum but also those seeking to enhance the skills of accountants in domains such as critical thinking, communication and sustainability. However our research has focused on a single site and therefore while our results are consistent with much of the previous literature they may not be widely generalizable. Future research might usefully consider the recommendations we have put forward above and examine the extent to which they deliver tangible results.

\section{References}

Avramidis, E and Norwich, B. (2002). Teachers' attitudes toward integration/inclusion - a review of the literature. European Journal of Special Needs Education, 17(2), 129-147. http://dx.doi.org/10.1080/08856250210129056

Berger, G. (1972). Introduction, in: L. Apostel, G. Berger, A. Briggs and G. Michaud (Eds) Interdisciplinarity: Problems of teaching and research in universities. Paris, Organisation for Economic Cooperation and Development, 53-54.

Beyer, J. and Lodahl, T. (1976). A Comparative Study of Patterns of Influence in United States and English Universities. Administrative Science Quarterly, 21, 104-129. http://dx.doi.org/10.2307/2391882

Bradbeer, J. (1999). Barriers to interdisciplinarity: disciplinary discourses and student learning. Journal of Geography in Higher Education, 23(3), 381-396. http://dx.doi.org/10.1080/03098269985326 
Braddock, R.D., Fien, J. and Rickson, R. (1994). Environmental studies: managing the disciplinary divide. The Environmentalist, 14(1), 35-46. http://dx.doi.org/10.1007/BF01902658

Brewer, G.D. (1999). The challenges of interdisciplinarity. Policy Sciences, 32(4), $327-337$. http://dx.doi.org/10.1023/A:1004706019826

Davies, M. and Devlin, M. (2007). Interdisciplinary Higher Education and the Melbourne Model, Conference Presentation, Philosophy of Education Society of Australasia.

Foster, J. (1999). What Price Interdisciplinarity?: crossing the curriculum in environmental higher education. Journal of Geography in Higher Education, 23(3), 358-366. http://dx.doi.org/10.1080/03098269985308

Franks, D., Dale, P., Hindmarsh, R., Fellows, C., Buckridge, M. and Cybinski, P. (2007). Interdisciplinary foundations: reflecting on interdisciplinarity and three decades of teaching and research at Griffith University, Australia. Studies in Higher Education, 32(2), 167-185. http://dx.doi.org/10.1080/03075070701267228

Frederick, W.C. (1998). One Voice? Or Many? Business Ethics Quarterly, 8(3), 575-579. http://dx.doi.org/10.2307/3857439

Hazelton, J. and Haigh, M. (2010). Incorporating Sustainability into Accounting Curricula: Lessons Learnt From an Action Research Study. Accounting Education: an international journal, 19(1-2), 159-178.

International Education Standard 4 (IES4): Professional Values, Ethics and Attitudes. (2005). International Federation of Accountants.

Nikitin, S. (2006). Three strategies for interdisciplinary teaching: contextualizing, conceptualizing and problem-centring. Journal of Curriculum $251-271$. http://dx.doi.org/10.1080/00220270500422632

Segovia, V. M, and Galang, A. P. (2002). Sustainable development in higher education in the Philippines: The case of Miriam College. International Journal of Sustainability in Higher Education, 3(3), $288-296$. http://dx.doi.org/10.1108/14676370210434741

Segreda, A. M. (2002). Sustainability and peace in Costa Rica: the case of the University of Costa Rica. International Journal of Sustainability in Higher Education, 3(3), $271-278$. http://dx.doi.org/10.1108/14676370210434723

Spain, J.W., Engle, A.D and Thompson, J.C. (2005). Applying Multiple Pedagogical Methodologies in an Ethics Awareness Week: Expectations, Events, Evaluation and Enhancements. Journal of Business Ethics, 58, 7-16. http://dx.doi.org/10.1007/s10551-005-1375-x

Steadman, M. (2000). An Interdisciplinary Health Care Accounting Class: Content, Student Response and Lessons Learned. Journal of Education for Business, May/June, $267-270$. http://dx.doi.org/10.1080/08832320009599026

Thomas, I. (2004). Sustainability in tertiary curricula: what is stopping it happening? International Journal of Sustainability in Higher Education, 5(1), 33-47. http://dx.doi.org/10.1108/14676370410517387

Verbitskaya, L. A., Nosova, N.B and Rodina, L.L. (2002). Sustainable development in higher education in russia: the case of St Petersburg State University. International Journal of Sustainability in Higher Education, 3(3), 279-287. http://dx.doi.org/10.1108/14676370210434732

Williams, J. and Elson, R.J. (2010). Improving Ethical Education in the Accounting Program: A Conceptual Course. Academy of Educational Leadership Journal, 14(4), 107-116. 